\title{
Reward and Recognition System-Key Behaviors to Benefit Employees and Businesses in Competitive Job Markets
}

\author{
Almas Sabir \\ College of Business Administration, University Of Hail, Hail, Kingdom Of Saudi Arabia \\ almas.sabir083@gmail.com
}

\begin{abstract}
In a competitive business climate, many businessmen are looking at improvements in quality while reducing costs. Meanwhile, a strong economy has resulted in a strict job market. So while small businesses need to get more from their employees, their employees are looking for more out of them. Employee reward and recognition programs are one method of motivating employees to change work habits and key behaviors to benefit a small business. This paper will highlight the outstanding performance of entrepreneurs by providing an edge to competitive corporate climate. In this paper we will also discuss how to improve, develop and implement reward program that will encourage communication between employees and management. When the reward is changed frequently, employees will be more surprised and the process will be more exciting. When employees are excited about rewards, they will work harder to achieve them.
\end{abstract}

Keywords: Rewards, Recognition, Employess, Communication, Corporate Climate, Management

\section{INTRODUCTION}

Every individual is motivated by different things. Money, awards or even just public praise are all parts of motivation. In this study, I would like to dig a little deeper and look at the forms of incentive and rewards programs. Over the years that has obviously changed and companies have come up with many new ways to motivate individuals.

Sometimes, simply receiving a paycheck is not enough of an incentive to keep employees dedicated and focused. Managers must think of new ways to hold an employee's attention and interest on a project, or the company as a whole. Many companies employ motivational tactics and rewards systems, both of which have advantages and disadvantages. One of the most common ways that companies put motivation programs into action is by putting together some type of incentive system like

- Companies use both positive reinforcement and negative reinforcement to motivate employees.

- Many managers believe that using positive motivation techniques encourages employees to produce more and better quality work.

- Companies reward their employees with both tangible goods, as well as praise.

\section{For example}

- A sales department may offer a monthly bonus to the highest earner. Not all tangible rewards come in the form of money.

- Some companies host free lunches, or give away company gear to good workers. Many managers choose to reward their best employees by simply praising them for a job well done, or by recognizing the hard work they put in to a project. 
The most important asset to any company is its people. Keeping employees happy in the workplace can make company a stronger, unwavering force within your industry. We took a look at what companies ranked in "Fortune's annual 100 Best Companies to Work for List" are doing to retain their employees and found several fantastic ideas. While some of these examples are a little extreme and might not fit into budget, I want you to be inspired and remember that every individual wants to be recognized for their good work.

Incentives go beyond the standard benefits program. We're talking about creating the best atmosphere for employee retention. We need more than just financial rewards. "Pay raises are generally effective for three months," says Richard Bead, vice-president of human resources for TELUS Corp; without further incentives, the motivation fizzles. While rewarding an employee with money is effective; money, once spent, can be forgotten. And not everyone is motivated by money, so non-financial rewards can be important alternatives.

Successful organizations understand the importance of developing a recognition and reward program to recognize the accomplishments and validate the work of their employees. These programs may be formal, offering material incentives for employees who achieve predetermined goals, or informal, providing positive feedback in the form of verbal praise. Perhaps, the most effective program is that which encompasses a range of recognition activities that reflects the unique culture of the organization.

Organizations hope to achieve a number of results through recognition and reward programs, including

- Creating a positive work environment

- Attracting and retaining employees

- Creating a culture of recognition

- Motivating and reinforcing high performance

- Increasing employee morale

- Supporting the organization's mission and values

- Encouraging loyalty

Many employers are resistant to adopting recognition and reward programs. They tend to dismiss these programs as high-cost, "feel-good" activities with few tangible benefits to the organization and its employees. However, research suggests that recognition, ranging from verbal praise to small non-cash awards, can be a cost-effective tool to raise employee morale and lower stress, absenteeism, and turnover. Furthermore, while employees benefit from recognition programs, the organization's adopting them also tend to see increased worker productivity and performance, improved profitability, higher retention rates, and decreased costs associated with turnover

\section{ANALYSis- EMPLOYEE RECOGNition}

This study has uncovered compelling evidence that there are clear differences between how men and women give and respond to recognition. While employers are currently developing schemes to appeal to all, it appears they should in fact be catering for the differing demands of men and women.

In general, women give and receive more recognition while men are more likely to give recognition in the form of a higher monetary value. Men become more engaged when there is a monetary reward involved whereas women tend to be better at just saying thank you 


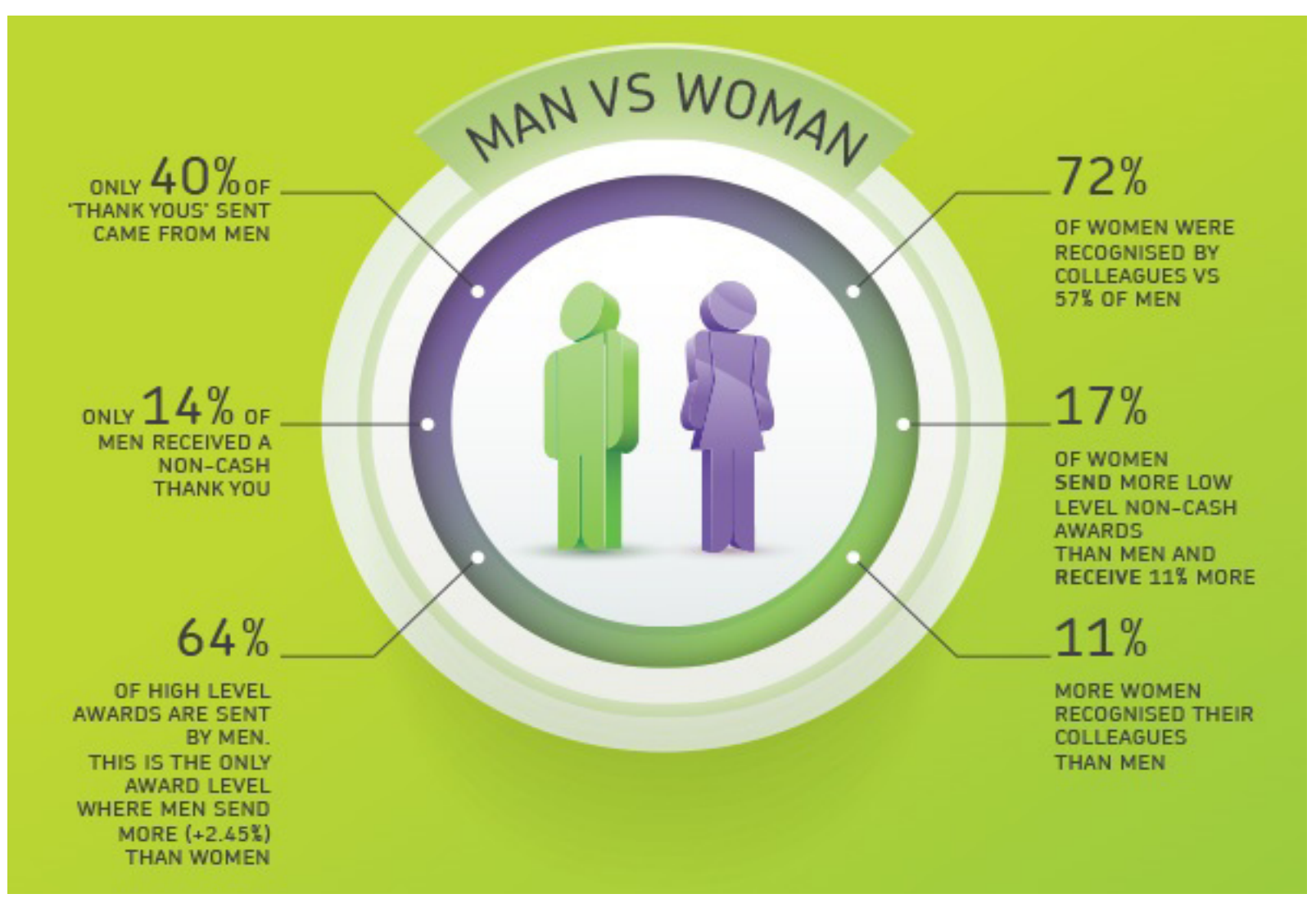

P\&MM has conducted an analysis of recognition generated and received by 30,857 employees within two large, nationwide recognition programmes in the financial services, and manufacturing sectors.

\section{Analysis-Compensation and Incentive}

With compensation contributing to the largest share of total expenses, it is imperative to ensure that total rewards programs are competitive, yet also aligned with business goals. These are the following important points that needs to be discussed

1. Understand the rate at which direct compensation costs are increasing and how this reflects the FTE (full time equivalent) count in the business-if your costs are higher and rising faster than your competition, then you are at a cost disadvantage, which will impact profitability.

2. Identify effective cost management options by analyzing where people costs can be flexed to reduce expenses or speed up revenue creation. For example, overtime spending, budgeted salary for open hiring requisitions, forecasted bonus expenses, and costs of contingent workers are all variables that can be analyzed.

3. Understand how entries to and exits from an organization impact the total compensation expenses.

4. Move beyond total rewards and consider your total cost of workforce-including taxes, long-term incentives, facilities, contingent labor, and other costs-to accurately plan for the future.

5. Improve productivity by implementing employee incentive programs that recognize and reward top performers. 


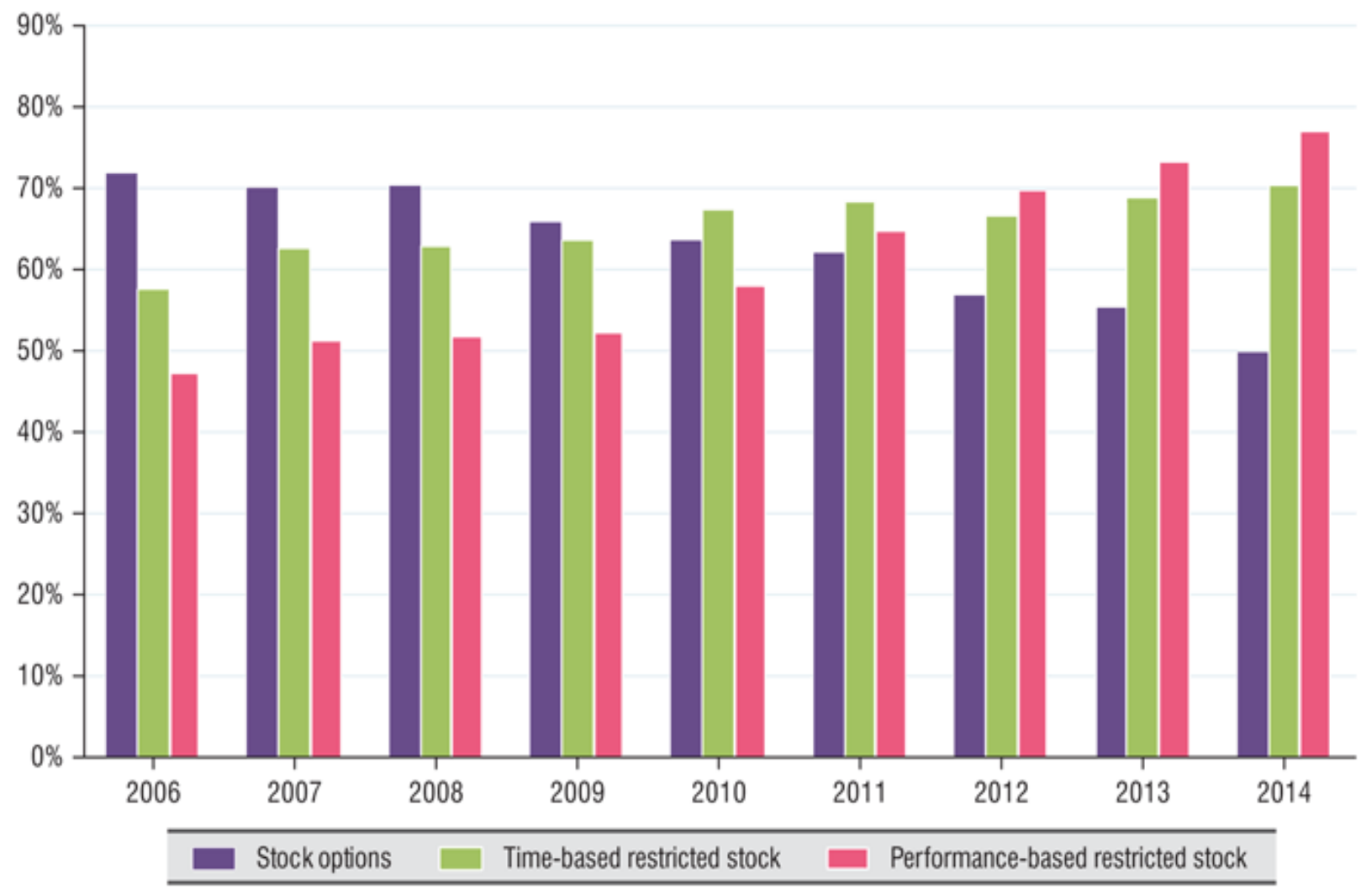

\section{Percentage of companies offering each type of incentive, 2006-14}

The percentage of companies offering stock options to top executives has declined from 72 percent to 50 percent since 2006, while the share offering performance-based restricted stock has grown from 48 percent to 77 percent. The share of companies offering time-based restricted stock grew from 58 percent to 70 percent.

But Fried says a problem with options and restricted stock is that CEOs will be rewarded—or penalized-for factors beyond their control. For example, falling or rising oil prices will have a big effect on an oil company's stock price. "I would like to see something that corrects for industry effects, and some companies do that," Fried says. One way is to have options and restricted stock vest only if the company's stock price improves more than those of competitors or if it beats the S\&P 500 .

Others say equity-based pay encourages CEOs to manipulate the stock price. "Stock buybacks are the critical way of manipulating the market and getting your stock price up fast and cashing in on it," says William Lazonick, co-director of the Center for Industrial Competitiveness at the University of Massachusetts, Lowell. When a company buys stock back from shareholders that reduces the number of shares on the market, automatically increasing the percentage of the company represented by each share, and thus usually hiking the price per share. Such repurchases drain money from a company's treasury that could be spent investing in its workforce, Lazonick says. "Buybacks should be illegal."

But when a firm has more cash than it can use in its current operations, buybacks are a wise move, says Murphy of the University of Southern California. "Managers have a tendency to waste that cash, and giving it back to shareholders who can invest it more productively elsewhere is a good thing." 
After analyzing I think an effective employee recognition system should be simple, immediate, and powerfully reinforcing.

We need to establish criteria for what performance or contribution constitutes rewardable behavior or actions. The Five Most Important Tips for Effective Recognition

- You need to make all employees eligible for the recognition.

- The recognition must supply the employer and employee with specific information about what behaviors or actions are being rewarded and recognized.

- Anyone who then performs at the level or standard stated in the criteria receives the reward.

- The recognition should occur as close to the performance of the actions as possible, so the recognition reinforces behavior the employer wants to encourage.

- You don't want to design a process in which managers select the people to receive recognition. Employees will see this type of process forever as managerial favoritism. Or, they will talk about it in words such as, "Oh, it's your turn to get recognized this month." This is why processes that single out an individual, such as Employee of the Month, are rarely effective.

\section{RECOMMENDATIONS}

In many organizations recognition and financial reward are joined at the hip. An employee does something above and beyond and receives a gift card or a lunch with the boss; a team achieves a goal and is rewarded with a party. These rewards, however, can backfire; they tell the employee that he or she is worth $\boldsymbol{n}$ dollars to the organization for some level of effort. In my opinion this approach misses the point of recognition: people are motivated by more than money. People crave positive feedback, recognition they put in extra effort, acknowledgement of leaders and peers, the glow that comes with knowing an achievement has been seen, appreciated and celebrated. I love this place. But I'm also realistic as I look at ways leaders can recruit and truly nurture current and future talent.

Financial reward is a great thing, don't get me wrong, but it's not the equivalent of recognition. Let's not kid ourselves. It's a short term solution. Neither is constant praise for average work. Recognition is a key tool in employee retention programs for a reason: people need more than constructive feedback and positive affirmation. They need recognition of extra effort. They need to "feel" it. This will never go away as a basic human need.

\section{An effective approach to employee recognition encompasses these key points}

In the moment: as much as possible, be timely. Catch people doing exemplary work and acknowledge their efforts. Don't be knee-jerk - showing up for work on time does not count in most cases. Be specific, descriptive and measured.

In context: recognition is most effective when it's given in the context of a larger goal or business-results-focused activity. Random affirmations are much less meaningful than those tied to a business goal. An employee who lands a big contract by putting in the extra effort needs to know you noticed, and understands the employee's effort to ensure business success. This matters a lot.

Appropriate in volume/scale: think back to the mom in the market. Was the praise she doled out appropriate in scale and volume? Not really. Here again randomness is not your ally. Recognition should match effort and results, or it loses meaning. This is where the complexity lives.

Volume 2

Page 5 
Authentic, not automatic: you have to mean it when you give employees recognition. This is my chief worry about automated recognition systems - they remove the human touch so important to effective recognition. Can we find a smart balance? Can we make social HR Tech software work?

Tied to the employee's perception of value: people know when they're valued, and they should have a good idea of their value to the organization. Monetary rewards can skew this notion of value, linking it to cash when it should be linked to appreciation of extra effort and smarts. Money is appropriate much of the time, but it's not the only - or even the most effective - motivator. Treat employees as valued team members, not as numbers. Most of the time it's the best way to really recognize a valued player.

There is HR Technology that's super sexy and relevant for engagement. I'm over thinking it at the moment. This is typical as we find the most meaningful ways to innovate the future of work. I'm excited about software and social applications for rock star leaders and workplace culture. It's all good. Now we seek to connect the most relevant, human and inspiring dots.

I have many thoughts about how we, as a society and a global social leadership community, handle recognition, but I'd like to hear what's on your mind. Please weigh in and tell me what recognition means to you, and how you've successfully recognized your employees and co-workers. Leaders jump in here too. Lead the revolution. You Rock.

\section{CONCLUSION}

The results and discussion indicated the relevance of individual and organizational factors in influencing the value that an individual associates with recognition. This present study summarizes the major learning of the study, recommends a basic framework of recognition for organizations and indicates the implications for practice. Suggestions for future research endeavors are also made.

To conclude this study I would like to highlight certain points which is necessary to take for consideration

1. The results of the study indicated insignificant role of individual demographic (age, sex) and functional factors (years of work experience, career stage and functional area) in determining the value of recognition for employees. That is, the value associated to recognition by employees is independent of their demographic or functional factors.

2. The employee choices as regards the delivery of recognition involved a formal setting, public forum, written form, monetary token, conferred by the senior and delivered after achievement of target. These choices were independent of individual characteristics; no differences were found across sector and across organizations in case of employee choices as regards delivery of recognition.

3. Offering praise and recognition costs nothing, but studies indicate that it can even be as effective as giving employees a financial reward. In 2008, strategy consultancy White Water Strategies reported that being praised can have the same impact on job satisfaction as being awarded a one per cent pay rise. Meanwhile, the Japanese National Institute for Psychological Sciences has investigated the neurological impact of praise, discovering that being paid a compliment activates the same part of our brain as receiving cash!

There's little doubt that praising and recognizing the efforts and achievements of others can bring about some very positive results in the workplace. Being praised makes the recipient feel good about them and this can help to boost their performance. Praise provides the kind of positive experience or 'uplift' that can increase employees' morale, motivation and engagement, and renew their commitment to their manager and the organization. For praise to have this kind of impact, however, it needs to be delivered effectively. Only genuine achievements should be praised, and managers should ensure their feedback is constructive and specific.

Volume 2

Page 6 


\section{REFERENCES}

1. http://www.inc.com/encyclopedia/employee-reward-and-recognition-systems.html

2. 20 Ways to Increase Employee Motivation Using Rewards, www.talkdesk.com/blog

3. About Employee Motivation \& Reward Systems by Amelia Jenkins, studio, http://smallbusiness.chron.com/

4. Rewarding Your Employees: 15 Examples of Successful Incentives in The Corporate World

5. Daniel, T., \& Metcalf, G. (2005). The fundamentals of employee recognition

6. http://staffmotivationmatters.co.uk/employee-recognition-analysis

7. www.experfy.com/workforce-analytics/compensation-and-incentive-analysis

8. http://businessresearcher.sagepub.com/

9. 5 Ways Leaders Rock Employee Recognition, http://www.forbes.com/

10. http://shodhganga.inflibnet.ac.in/bitstream/10603/3354/17/17_chapter\%207.pdf

\section{AUThor's Biography}

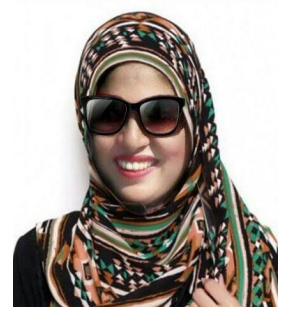

Almas Sabir, received the PhD degree in Management from Himalayan University, India in 2016. She received MBA degree in Management from U.P Technical University in 2007. From 2011-2016, she worked as a Lecturer in University of Hail, Hail, Kingdom of Saudi Arabia, India.

Citation: Almas Sabir, "Reward and Recognition System-Key Behaviors to Benefit Employees and Businesses in Competitive Job Markets", American Research Jornal of Business and Management; Volume 2, 2016; pp:1-7

Copyright (C) 2016 Almas Sabir, This is an open access article distributed under the Creative Commons Attribution License, which permits unrestricted use, distribution, and reproduction in any medium, provided the original work is properly cited. 